\title{
HUMOR E INCLUSÃO DE TEMAS DE INTERESSE PÚBLICO EM UMA OBRA EM ESPALHAMENTO: UMA ANÁLISE DO CASO OLIMPÍADAS 2016
}

\author{
Humor and inclusion of public interest topics in a spreading content: an \\ analysis of the 2016 Olympics case
}

Humor e inclusión de temas de interés público en una obra en progagación: un análisis del caso Olimpiadas 2016

\author{
Edson Fernando Dalmonte \\ Professor do Programa de Pós-Graduação em \\ Comunicação e Cultura Contemporâneas da Universidade Federal da Bahia. \\ edsondalmonte@gmail.com
}

Pedro Carlos Ferreira Souza Doutorando do Programa de Pós-Graduação em Comunicação e Cultura Contemporâneas da Universidade Federal da Bahia. pedrocfsouza@gmail.com

\section{Resumo}

Parte-se dos distintos modos de circulação das Olimpíadas 2016, entendidas aqui como uma obra narrativa midiática. Para além do modo convencional, no qual meios tradicionais veiculam/repercutem a realização do evento esportivo, múltiplos discursos públicos se agregam na formação dialógica de um conteúdo em espalhamento na rede. A profanação midiática se destaca como um movimento político de retomada do controle comunicativo, que se manifesta ao longo de um processo de adaptação participativa através de diferentes plataformas. $\mathrm{O}$ humor surge como uma expressão conveniente para a investigação de um modo mais desordeiro de ressignificação agenciada por interagentes que interagem com a obra em questão. Neste sentido, quatro casos foram selecionados visando 1) abordar a capacidade de incorporação de pautas sociais à obra em questão pelo uso do humor e 2) a promoção de tais pautas na esfera de visibilidade pública.

Palavras-chave: Profanação. Participação. Sites de Redes Sociais.

\section{Abstract}

We start from the different modes of circulation of the "Olympiad 2016", understood here as a narrative media work. In addition to the conventional way, in which traditional media vehicles convey/rebound the realization of the sporting event, multiple public discourses are added in the dialogical formation of a spreading content in the network. The media profanation stands out as a political movement for the resumption of communicative control, which is manifested through a process of participatory adaptation through different platforms. Humor emerges as a convenient expression for the investigation of a more disorderly way of 
resignification waged by agents interacting with the work in question. In this regard, four cases were selected aiming 1) to address the capacity of incorporating social themes into the work in circulation by the use of humor and 2) the promotion of such themes in the sphere of public visibility.

Key words: Profanation. Participation. Social Networks Site.

\section{Resumen}

Se parte de los distintos modos de circulación de las Olimpiadas 2016, entendidas aquí como una obra narrativa mediática. Además del modo convencional, en el cual medios tradicionales vehiculan / repercuten la realización del evento deportivo, múltiples discursos públicos se agregan en la formación dialógica de un contenido en propagación en la red. La profanación mediática se destaca como un movimiento político de reanudación del control comunicativo, que se manifiesta a lo largo de un proceso de adaptación participativa a través de diferentes plataformas. El humor surge como una expresión conveniente para la investigación de un modo más disruptivo de resignificación agitada por agentes que interactúan con la obra en cuestión. En este sentido, cuatro casos fueron seleccionados para 1) abordar la capacidad de incorporación de pautas sociales a la obra en cuestión por el uso del humor y 2) la promoción de tales pautas en la esfera de visibilidad pública.

Palabras clave: Profanación. Participación. Sitios de Redes Sociales.

\section{INTRODUÇÃO}

Diversos fatores tecnológicos e culturais propiciam a popularização de um ambiente em rede favorável à inteligência coletiva, aumentando a percepção de centralidade dos usuários no processo de circulação atrelado à articulação e reordenamento de sentidos. Portanto, observadas as possibilidades de interação no atual contexto comunicacional, notamos a consolidação de instâncias discursivas que facilitam a participação de agentes até então pouco óbvios. Estas instâncias estão continuamente se dispondo através de múltiplas plataformas interativas.

O presente trabalho tem como foco a análise das adaptações apropriativas que participantes diversos fazem de obras midiáticas no ambiente web, com especial ênfase na atuação de usuários que utilizam o humor como modo de ressignificação de produtos culturais oriundos da mídia massiva. As manifestações de culturas envolvidas neste processo discursivo de adaptação criativa se configuram como complementos que atualizam a obra midiática. Produtos culturais provenientes da mídia massiva são frequentemente apropriados em múltiplas plataformas, atualizados por múltiplos atores participativos e prolongados em rede virtual (JENKINS et al, 2013; SHIFMAN, 2014; SHIRKY, 2011). 
Este prolongamento é perceptível principalmente se considerarmos que o produto passa a ocupar novas plataformas e novos ambientes de mídias, como os blogs e as linhas do tempo pessoais em sites de redes sociais. Neste sentido, esta pesquisa tem um duplo propósito: identificar semelhanças entre fluxos discursivos que auxiliam na composição do produto midiático em recirculação na rede e, além disso, avaliar a inserção de temáticas sociais relevantes e negligenciadas, ou abordadas sem aprofundamento, ao longo da obra prolongada narrativamente. Tal processo pode ser compreendido como uma forma de promoção de um debate público sobre questões sociais que emergem das 'margens' comunicacionais.

Assim, buscamos compreendemos que não só os usuários exercem influência sobre as obras, como tais obras também influenciam o comportamento dos usuários. À medida que se espalha na rede, ela induz mais pessoas a participarem do processo coletivo de cocriação da obra em questão, agenciando e se permitindo agenciar continuamente. Centramos nossa investigação no prolongamento participativo de uma obra que se destacou no ciberespaço a partir de agosto de 2016, a saber, as Olimpíadas do Rio de Janeiro. Consideramos que este evento foi sistematizado como obra cultural na mídia, embora não seja um produto midiático massivo convencional, como filmes ou telenovelas.

Uma série de fatores facilitaram tal seleção, sendo o primeiro deles a capacidade, intrínseca à obra, de espalhamento e acúmulo de sentidos. Além disso, neste processo de ampliação narrativa e construção de fluxos adaptativos, houve uma ênfase preponderante para circulação participativa agenciada por usuários sem vínculos formais com conglomerados de mídia ou veículos comunicativos. Através da leitura flutuante de diversos conteúdos produzidos por perfis e páginas humorísticas no Facebook, identificamos semelhanças entre fluxos que auxiliam na composição destas obras em recirculação na rede e analisamos as estratégias discursivas utilizadas pelos interagentes no processo de expansão de conteúdos de mídia.

Dada essa conjuntura, nosso caminho investigativo envolve o esforço para compreender justamente como o deslocamento adaptativo do conteúdo que perpassa diferentes plataformas tecnológicas impacta no universo discursivo da obra. Abordar a apropriação que estes atores fazem como um processo de adaptação entre plataformas ajuda a enxergar melhor o relacionamento entre textos verbais e não-verbais no trânsito de significados entre diferentes produções culturais. 
Alguns produtos midiáticos, tais quais séries de TV, filmes ou romances literários juvenis, mobilizam altos níveis de vínculo e engajamento por parte dos consumidores caracterizados como heavy users $^{1}$ em sites redes sociais. Tais usuários dominam áreas de discussão de modo a proteger sua fonte de admiração, internalizando mecanismos de proteção da obra genetriz e de regulação ao processo participativo. Este tipo de usuário está disposto a aceitar regras das instâncias produtoras e a instaurar algumas outras formas de vigilância no intuito de proteger a obra midiática, numa espécie de 'participação concordante'. Age, inclusive, distribuindo reconhecimento e benesses aos que compartilham de suas posições e punindo (algumas vezes com o ostracismo) aqueles que discordam delas (FECHINE \& MOREIRA, 2015).

Apesar desta ser uma tendência, nossa proposta não tem como foco a análise deste tipo de estratégia, seja ela comercial ou afetiva. O que caracteriza nossa preocupação epistemológica é justamente o argumento de que a participação nos ambientes digitais pode ser (ou parecer ser) espontânea, desapegada da ideia de que a participação dos usuários deve ter alguma intenção finalística em concordância com os objetivos dos produtores. $\mathrm{O}$ termo profanação é trabalhado pelo filósofo italiano Giorgio Agamben (2007) como um ideal de negligência com os dispositivos que controlam a ação humana e disciplinam os modos de uso de certo recurso.

Nas construções narrativas da obra Olimpíadas 2016, a divergência é percebida na aparição de intenções diversas por parte dos interagentes. A existência de múltiplas intencionalidades em jogo caracteriza um espalhamento difuso e abrangente. Portanto, esta foi outra questão relevante para a escolha da obra a ser analisada. Podemos sintetizar que nosso foco de análise são as participações profanatórias dos indivíduos em sites de redes sociais. Neste sentido, entendemos a controvérsia entre os modos de ação dos usuários como elemento constitutivo da cultura participativa.

Vistas de tal modo, as participações não devem se sujeitar a uma forma de governo ou controle explícito por esfera agenciadora. E como não há objetivo estratégico a ser alcançado pela adaptação criativa aparentemente espontânea dos usuários, não existe como medir a qualidade de uma adaptação por sua eficiência. Se toda participação de usuários no sentido de expandir narrativamente um conteúdo midiático colabora para atualizá-lo a uma nova plataforma e, consequentemente, a um novo nicho cultural, não há como qualificar uma

\footnotetext{
${ }^{1}$ Grupo de consumidores que assimila grandes quantidades de informações, capaz de detectar tendências e padrões que serão seguidos pelo consumidor casual.
} 
expansão de maior ou menor impacto, independentemente de quais sejam as finalidades da esfera de produção do conteúdo matriz.

\section{A PROFANAÇÃO MIDIÁTICA}

Todo discurso midiático faz uso de aparatos técnicos, seja para manutenção da sacralização da palavra, que caracteriza o rompimento entre homem e mídia, seja para seu contrário: a profanação e a restauração do poder de comunicar ao homem. O que distingue os dois, é o jogo com componentes do dispositivo enunciativo que desordena a noção de temporalidade e espacialidade para o consumo. A profanação desestabiliza os componentes internos dos dispositivos técnicos, potencializando a equalização das posições de negociação entre distintos polos comunicativos, de maneira a aumentar a fluidez para consumo das obras midiáticas (DALMONTE et al, 2015; AGAMBEN, 2007).

Essa fluidez representou um dos principais desafios metodológicos na seleção do corpus da pesquisa, porque, uma vez ressignificada, a obra passa a se organizar em sequências, dificultando a formalização de uma unidade para observação. Conforme Shifman (2014), as adaptações criativas ocorrem sempre como um conjunto (ou um acervo) de conteúdos, não sendo possível traçar nenhuma consideração caso suas aparições forem observadas fora do contexto geral, sem uma análise do fenômeno como um todo.

O limite estrito entre o produto midiático e o discurso que o público constrói sobre ele é muitas vezes embaçado em função da fluidez textual e, em alguns casos, este limite praticamente não existe (DALMONTE, 2009, p. 121). Em parte, isso se explica pelo fato da ampliação do texto original ocorrer na web tanto por elementos especializados, quanto por vias alternativas, formadas a partir da relação entre usuários em rede. Essa relação é culturalmente facilitada e incentivada, permitindo desdobramentos que se espalham pela web, de autorias diversas, mas conectados por um assunto em questão (JOHNSON, 2001; DALMONTE, 2009; ZAGO, 2013).

A propensão socialmente adquirida do sujeito para criar enquanto usa as palavras num processo de adaptação é acompanhada pela capacidade historicamente construída de instituições diversas para dominar e regular os atos de fala (DALMONTE, 2012). As estratégias e interesses por parte das esferas de produção tradicionais existem e se fazem presentes por meio de dispositivos que estão sempre inscritos numa relação de poder e, como tal, são resultado do cruzamento dessas relações de poder com as relações de saber 
subsequentes (AGAMBEN, 2009, p. 29). A ideia de dispositivo como instância de controle está ligada de modo intrínseco ao termo "governamentalidade" na obra de Michel Foucault (2008), sendo ambos os conceitos indissociáveis ao exercício de poder nas suas mais distintas formas.

O autor se ocupa da técnica geral de governo dos homens que, baseada na transferência, na alienação ou na representação da vontade dos indivíduos, teria dado origem a uma nova ideia de poder, que formulou a constituição do Estado moderno (FOUCAULT, 2008). Num segundo momento, o termo governamentalidade não se restringe apenas às práticas governamentais constitutivas de um regime de poder particular, passando a abranger "a maneira como se conduz a conduta dos homens", servindo assim como um leque mais variado para estudo das micro relações de poderes (SENELLART, 2008, p. 532).

O dispositivo é um mecanismo de poder com dimensões múltiplas, que pode ser percebido na metáfora do panóptico foucaultiano: a disseminação sistemática de dispositivos disciplinares com a finalidade de permitir vigilância e mecanismos de controle cada vez mais eficientes sobre as pessoas. A ideia sustentadora é que, por mais que a linguagem seja performática e tenha capacidade de dar forma aos objetos sobre os quais se fala, ela ainda sofre uma imposição de norma relativa ao panóptico, uma exigência que não é resultado da vontade de ninguém em específico. Segundo Klein (2017), no dispositivo entendido por Foucault, as ações individualizadas não têm tanta importância quanto as ações relacionadas e os resultados do conjunto, de modo que "as ações sociais não podem ser compreendidas como dos indivíduos, mas sim dos dispositivos, onde cada um opera uma parte do conjunto de ações que o constituem" (KLEIN, 2007, p. 216-217)

Ao expandir a noção apresentada por Foucault, Agamben (2007, p. 41) abrange como dispositivo as coisas cujas conexões com o poder não se apresentam da maneira mais obviamente perceptível ou definida:

não somente, portanto, as prisões, os manicômios, o Panóptico, as escolas, a confissão, as fábricas [...] cuja relação com o poder é num certo sentido evidente, mas também com a caneta, a escritura, a literatura, a filosofia, a agricultura, o cigarro, a navegação, os computadores, os telefones celulares, os computadores e - porque não - a própria linguagem (AGAMBEN, 2009, p. 41).

Para Agamben (2007), como os dispositivos de poder se estabelecem a partir da captura de aspectos inerentes aos indivíduos, seu cancelamento não ocorre por negação, mas por um processo de profanação. Enquanto a sacralização, raiz dos dispositivos, se caracteriza 
pela transferência da coisa à esfera privada, a profanação é, por sua vez, restituí-la ao livre uso dos homens desativando os dispositivos de poder. Profanar é, portanto, devolver algo ao uso comum, por meio da mudança de status da aura daquilo que estava separado. Isto não significa cancelar as separações, mas sim aprender a fazer um novo uso delas, a brincar com elas pela via do humor, por exemplo. "Há um contágio profano, um tocar que desencanta e devolve ao uso aquilo que o sagrado havia separado e petrificado" (AGAMBEN, 2007, p. 66).

Neste sentido, a profanação da linguagem se mostra como um desafio, já que outros tipos de dispositivos buscam neutralizar qualquer tentativa neste sentido. "Os dispositivos midiáticos têm como objetivo [...] neutralizar esse processo profanatório da linguagem como meio puro, impedir que o mesmo abra a possibilidade de um novo uso, de uma nova experiência da palavra" (AGAMBEN, 2007, p.76). Se, por um lado, um novo ator se dispõe a romper com o núcleo sagrado de uma obra midiática, buscando trazê-la ao uso comum "dos homens"; por outro, alguns veículos de mídia tradicional podem buscar governar este movimento espontâneo (FECHINE \& MOREIRA, 2015).

Amaral, Souza e Monteiro (2015) defendem que é possível que uma pessoa participe de um processo midiático advindo de um veículo hegemônico e, ao mesmo tempo, aja politicamente para resistir a esta hegemonia. As autoras entendem essa participação como uma microresistência cotidiana de natureza dualística, "o que torna o fenômeno complexo na observação da relação entre a indústria do entretenimento, participação política, cultura pop e mobilização social" (AMARAL et al, 2015, p. 152). Para entender a resistência a um sistema que não rompe com ele, é necessário compreender que os usos alternativos aos itinerários previamente previstos por corporações em seus produtos também caracterizam modos de se resistir.

\section{A CONSTRUÇÃO DIALÓGICA DE OBRAS MIDIÁTICAS}

As considerações de Agamben (2007) mostram-se necessárias para compreendermos como o jogo de forças entre mídia tradicional e consumidores participativos abre caminho para um uso mais popular da linguagem e da cultura ${ }^{2}$. Os usuários, ao introduzirem uma

\footnotetext{
${ }^{2}$ Coelho (2008) propõe um uso da Cultura como forma de ampliação da esfera do ser, ou seja, um modo de vida mais condizente com a contemporaneidade, em que se preze pela mudança constante e por novas experiências: "quando se retira do conjunto de atos, atitudes, comportamentos, ideias, crenças, práticas e representações, aquilo que configura o habitus, o que resta é a cultura" (COELHO, 2008, p. 32). Se a cultura é o domínio dos símbolos, este domínio deve vigorar para fins profanatórios, ou seja, de rompimento com a manutenção do que se está em vigência, daquilo que aparenta ser naturalmente constituído e que dificilmente se questiona.
} 
linguagem mais particular a uma obra midiática, acabam se apropriando de um conteúdo produzido por veículos profissionais, restituindo o livre uso da palavra e, com isto, profanando o ato comunicativo por romperem com a sacralização que separava homens e mídia, tendo em vista os fluxos "tradicionais".

Bakhtin (1981) considera que toda palavra comporta duas faces, uma determinada pelo fato de preceder de alguém e outra por se distinguir para alguém. "A palavra é uma espécie de ponte lançada entre mim e os outros. Se ela se apoia sobre mim numa extremidade, na outra apoia-se sobre o meu interlocutor. A palavra é o território comum do locutor e do interlocutor” (BAKHTIN, 1981, p. 115). Por isto, diferente da retórica, o diálogo não tem como fim o aniquilamento do adversário, visto que isto impossibilitaria o próprio poder dialógico que mantem a palavra viva (BAKHTIN, 1997, p. 391).

As possibilidades atuais de criações de narratividades na web explicitam, de maneira cada vez mais pujante, a polifonia e o dialogismo de que trata Bakhtin. Simultaneamente, a carnavalização é apresentada como modo de rompimento com os dispositivos de poder:

Segundo Bakhtin, o medo é emoção que mais contribui para o poder e para a seriedade da cultura oficial [...] Bakhtin nos sugeriu que uma das respostas para este medo era a criação das formas "populares-festivas", que permitiam uma trégua, no formato de transgressões, restritas e permitidas temporariamente, das normas sociais e literárias (HUTCHEON, 2010, p. 260).

A carnavalização adere a essa visão vasta e popular, que se opõe ao sério, ao individual, ao dogmático e à discriminação: “de fato, esta 'transgressão' do código linguístico (lógico/ social) no carnaval só é possível e eficaz porque ela se confere uma outra lei. O dialogismo não é a 'liberdade de se dizer tudo': é uma zombaria [...] que é contudo, dramática, um imperativo diverso" (KRISTEVA, 1974, p. 69).

Por meio de uma disputa dialógica mobilizada pelo levantamento de uma controvérsia, novas camadas de significação podem ser adicionadas a uma obra. Este modo contínuo de participação, em que os usuários ganham competência e reconhecimento para propor novos itinerários, implica um jogo de aproximação e afastamento no qual se "reproduz" um discurso ao mesmo tempo em que o desvirtua (FELINTO, 2008). Para Felinto (2008, p. 41), "se a lógica da produção cultural clássica pregava o distanciamento e a reverência, a nova lógica opera com a proximidade e a paródia". O texto humorístico cada vez mais é exposto através 
de montagens e remixagens entre conteúdos da cultura de massa que expressam manifestações coletivas e individuais em sites de redes sociais.

\section{AS OLIMPÍADAS 2016}

Em 2016, de 5 a 21 de agosto, o Rio de Janeiro sediou os Jogos da XXXI Olímpiadas. É importante compreender de antemão que este evento se apresenta na forma de textos midiáticos, dada a sociedade midiatizada que vivemos (HEPP et al, 2015; HJARVARD, 2012; DEUZE, 2013). Isto significa que é praticamente impossível separar as Olimpíadas da cobertura midiática dos Jogos Olímpicos.

Trata-se de um evento pensado para a mídia e desenvolvido na mídia e com mídia. Segundo Bourdieu (1997), os Jogos Olímpicos têm um referencial aparente, que é a manifestação do "real", e um referencial oculto, que é o conjunto das representações deste espetáculo filmado e veiculado pelas redes de TV. O primeiro referencial trata do espetáculo esportivo, do confronto dos atletas vindos do mundo todo "que se realiza sob o signo de ideais universalistas" (p. 123), enquanto o segundo trata do espetáculo olímpico midiatizado, fruto de uma transmutação simbólica na qual "a produção da imagem televisiva desse espetáculo, que, enquanto suporte de spots publicitários, torna-se um produto comercial que obedece à lógica de mercado" (p. 124)

Consideramos que os Jogos têm sua forma midiática atualizada (ou seja, ganham corporeidade na mídia) no momento da transmissão televisiva ao vivo de sua cerimônia de abertura $^{3}$, no dia 5 de agosto de 2016. Alguns fatores corroboraram para escolha deste momento: 1) a própria expressão "abertura das Olimpíadas" age como um aspecto cerimonial que transmite aos agentes envolvidos a ideia de que a obra tem seu início a partir daquele ponto; 2) a cobertura massiva e instantânea realizada pelos veículos de mídia, principalmente os televisivos, cria a sensação de unicidade que centraliza este momento de atualização em um único ponto temporal, evitando possíveis dissidências sobre seu início; 3) o alto índice de consumo síncrono por parte da audiência, com mais de 28 milhões de pessoas acompanhando a cerimônia ao vivo pela $\mathrm{TV}^{4}$.

\footnotetext{
${ }^{3}$ A cerimônia na íntegra está disponível em: https://goo.gl/aKmK9q . Acesso em: 27/08/2018.

${ }^{4}$ Segundo dados do Ibope. Disponível em: https://goo.gl/6fmpnF . Acesso em: 06/12/2017.
} 
A abertura das Olimpíadas funcionou como um gatilho para o início da construção coletiva e dialógica da obra enquanto narrativa midiática. Os múltiplos textos midiáticos que formaram tal obra podem ter maior ou menor controle por parte de veículos e meios tradicionais. A partir disto, propomos estratificar o movimento circulatório em etapas que se expressam por casos, relacionados com as Olimpíadas, que se tornaram discursivamente relevantes para seu desenvolvimento narrativo por meio da mobilização coletiva dos usuários. Neste sentido, selecionamos quatro casos que reiteradamente se apresentaram e influenciaram os roteiros da obra após seu início: 1) Fora-Temer; 2) Quem criou o avião; 3) Moça se recusa a ajudar turista; 4) Nadadores americanos mentem sobre assalto. Percebemos o uso frequente do humor como recurso para inserção de grandes temáticas sociais em todos estes casos.

Nossa análise se atém às adaptações que pareçam negligenciar interesses comerciais, escapar às formas de controle de um criador "oficial" e estejam ancoradas principalmente na manifestação criativa e humorada. O verbo 'parecer', em destaque, marca a dificuldade em delimitar os interesses dominantes (de alguma instituição que venha a se beneficiar direta ou indiretamente) das adaptações: a experiência dos usuários na rede de ressignificações é permeada por mecanismos que constituem e controlam a ação humana.

\subsection{Análise dos casos}

O conjunto de publicações que abarcaram o evento intitulado "Fora Temer" aborda a reação dos usuários ao panorama político nacional. Trata-se de um evento marcado por publicações que se posicionaram contrariamente à nomeação de Michel Temer ao posto máximo de comando político no país.

Tal tema não se limita, portanto, à obra Olimpíadas 2016, mas dada a constância com a qual foi abordado no decorrer da obra em questão, consideramos que ele se insere como parte significativa na constituição desta. Este movimento circulatório de produções participativas na mídia vincula-se primeiramente à situação institucional da nação, se desenvolvendo numa crescente ao longo dos meses que antecederam os jogos olímpicos, acompanhando a crise política agravada no país após as eleições de 2014 e do movimento de instabilidade intensificada pelo prosseguimento do impeachment de Dilma Rousseff. Corrobora para essa associação entre os dois movimentos circulatórios o fato de que o processo de impeachment se prolongou durante parte do período que a competição olímpica se desenvolveu. 
Nos dias que se seguiram, pessoas passaram a ser impedidas pelo Comitê Olímpico Internacional de se manifestarem politicamente durante os jogos, seja através de cartazes ou gritos, sob a ameaça de serem expulsas das arenas de competição. O que percebemos, a partir de então, foi a pre
que participavam
em espalhamento
digital do texto
abertura $^{5}$.

Figura 1 - Texto na mão de atleta é alterado para "Fuera Temer"

Fonte: https://goo.gl/jMsChv . Acesso em: 20/02/2017.

Além da alteração de texto, outro recurso paratextual ${ }^{6}$ percebido na construção coletiva deste evento foi a soma de novos textos pelo usuários. Este outro modo com que a temática política foi apresentada na obra analisada ocorreu pela atitude de espectadores que burlavam a proibição do Comitê Olímpico para se manifestar durante a apresentação das competições e publicavam tais ações de rechaço em suas redes sociais (FIG. 2).

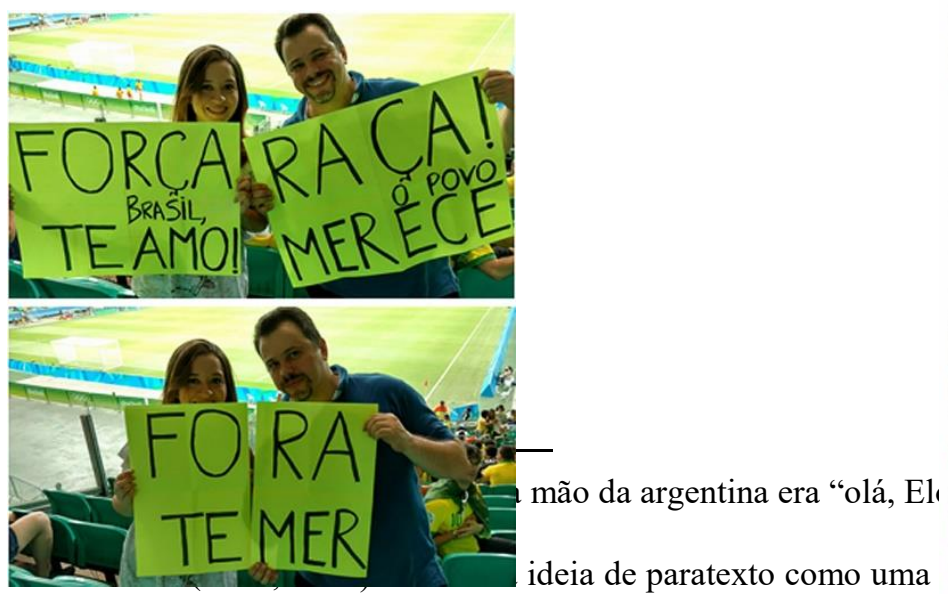

em um texto, um umbral sem limite rígido. Trata da relação qı
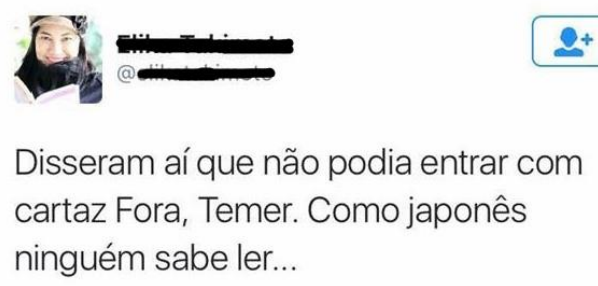

textos que o referenciam (GENETTE, 1989, p. 11). O paratexto cumpre sua tunçao paratextual quando seu criador é capaz de exercer uma ação enquanto diz algo acerca do texto (GENETTE, 2009, p. 17). Os paratextos produzidos por usuários se sobrepõem aos textos, adicionando novas significações à obra, assim como as anotações, grifos e comentários de leitores diversos nas laterais de livros comunitários. 
Figura 2 - Público dos jogos burla regra e posta em suas redes.

Fontes: https://goo.gl/Kj0Wgd ; https://goo.gl/xzDers . Acesso em: 15/02/2017

Ao publicarem e incentivarem tais ações nos sites de redes sociais, essas pessoas possibilitam um maior espalhamento da obra midiática na rede, alterando os itinerários inicialmente previstos enquanto criticam o governo durante o desenvolvimento da obra.

Assim como estes, diversos outros indivíduos passaram a buscar formas de manifestação distintas e tiveram suas ações compartilhadas por páginas de cunho humorístico, político e, inclusive, páginas de veículos noticiosos. Com isto, tais usuários acabaram criando um novo rumo narrativo para esta obra cultural e, consequentemente, ajudaram a promover um debate político na esfera pública por meio do uso do recurso humorístico.

Já o caso da polêmica sobre quem criou o avião teve início durante a cerimônia de abertura, quando uma réplica do 14 bis sobrevoou o estádio do Maracanã. Mas o que era, até então, uma homenagem ao mineiro Alberto Santos Dumont foi motivo de discussão especialmente entre usuários brasileiros e americanos nos sites de redes sociais ${ }^{7}$.

É possível que os produtores do evento esperassem uma construção narrativa no sentido de contestação pela imprensa e por parte dos usuários norte-americanos, dada a previsibilidade de que tais agentes, em geral, não reconheçam ao brasileiro o status de "pai da aviação". No entanto, é o usuário brasileiro, e não a imprensa tradicional, quem mais se engaja num embate dialógico em vias de alterar os rumos da discussão. Com isso, ganha destaque a questão que, inicialmente, não tinha tanta centralidade na obra. Por meio do uso de sátiras ao consenso estadunidense sobre a criação do avião, o público promove a discussão do tema conferindo-o status de evento narrativo, que se insere na obra em questão e a atualiza a novos contextos midiáticos (FIG. 3).

Interessante perceber que alguns usuários tecem opiniões na seção de comentários das publicação, expandindo ainda mais o universo narrativo do fato em questão. Uma pessoa comenta na publicação que apresenta a segunda imagem da figura 3: "A maior prova de que o avião é invenção de um mineiro é aquele sistema usado na hora de pousar ser chamado de

\footnotetext{
${ }^{7}$ Não somente usuários, como veículos de imprensa e jornalistas norte-americanos contestaram a "paternidade" da aviação durante a exibição da homenagem a Santos Dumont na festa de abertura. Para muitos norteamericanos é inconteste a ideia de que quem realmente inventou o avião foram seus compatriotas, os irmãos Orville e Wilbur Wright.
} 
'trem' de pouso. Caso encerrado". O que se percebeu, em geral, foi uma defesa engajada por parte dos usuários brasileiros da tese nacional de que Santos Dumont é o inventor do avião. A tutela deste argumento por vezes ocorreu através da ironia com o feito dos Wright, comparando-o a uma catapulta ou estilingue.
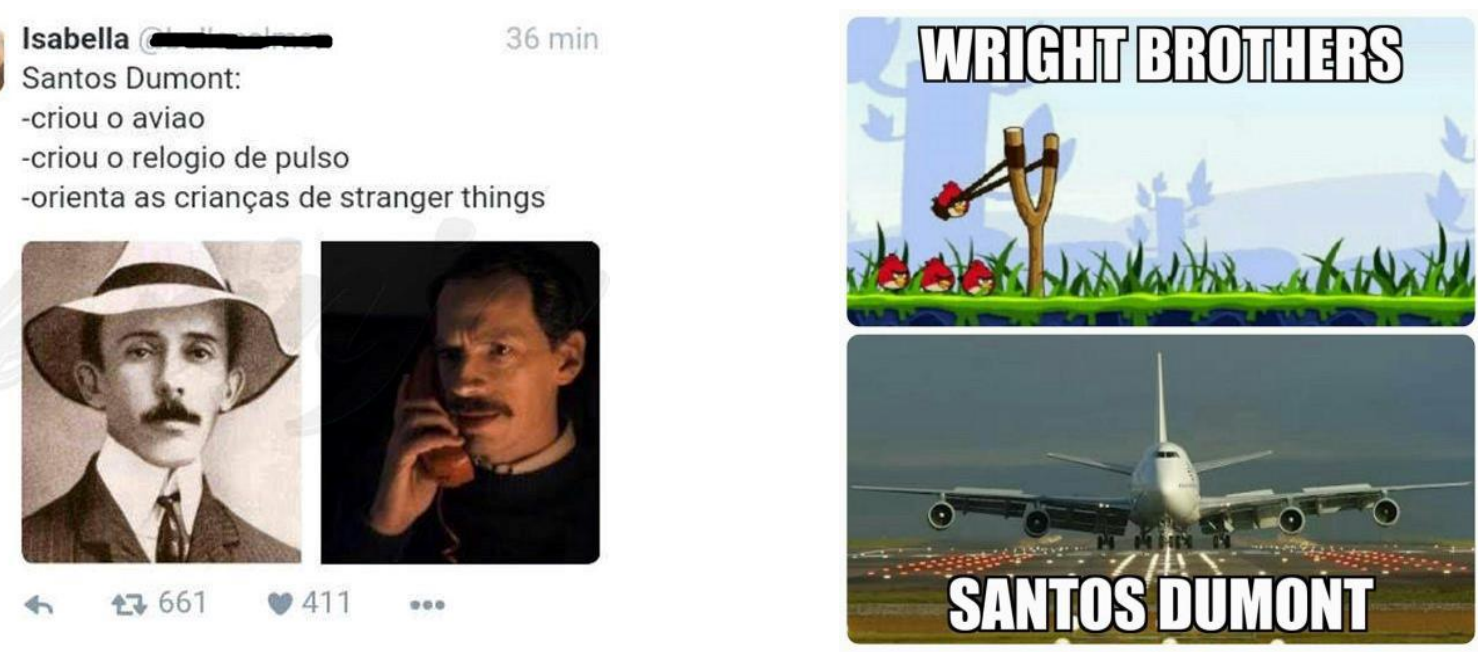

Figura 3 - Publicações satirizam o consenso norte-americano sobre a invenção do avião.

Fontes: https://goo.gl/ScCVYs / https://goo.gl/qF7w74 ; https://goo.gl/jUJJzb . Acesso em: 16/02/2017

O engajamento mobilizado na propagação deste evento promoveu, pelas bordas midiáticas, questões sociais relevantes como soberania nacional, imperialismo cultural e memória coletiva. Tais evidências reforçam ainda que estamos tratando de uma obra aberta por essência, principalmente por não terem uma relação direta com o evento olímpico previamente determinado pelas esferas de produção.

Isto significa que o desenvolvimento de uma obra que se difunde espaço/temporalmente pode vir a mobilizar efeitos que posteriormente influenciarão o próprio desenvolvimento da obra, num movimento sistêmico e contínuo de causa e consequência. Foi assim também com o caso da menina que se recusou a ajudar uma turista em inglês. Ao postar um texto no qual narrava a situação em que se recusava a ajudar uma turista que não falava português (FIG. 4), uma usuária brasileira teve sua publicação amplamente recirculada na mídia. Seu comportamento, avesso ao uso de língua estrangeira por parte dos turistas durante a realização das Olimpíadas, incitou uma tomada de posição pelos outros usuários na internet, que mobilizavam argumentos sérios para defender ou criticar a conduta exposta no texto original. 


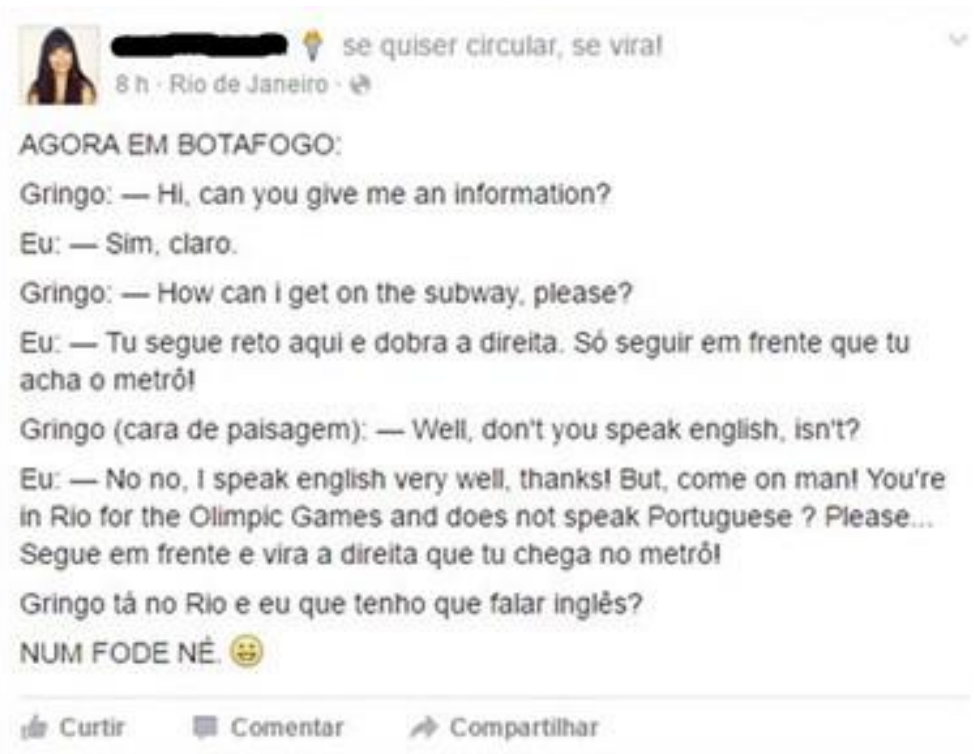

Figura 4 - Usuária conta no Facebook que se recusou a ajudar um estrangeiro em inglês. Fonte: https://goo.gl/Pvjgti . Acesso em: 16/02/2017

No entanto, nos interessa a observação da adaptação criativa popular em que prevalecia um viés humorístico. Neste caso, a defesa ou crítica à atitude da menina poderia persistir, mas, na maior parte das vezes, ocorria de maneira indireta, predominando a busca pela manutenção de laços sociais e pela criação de capital social na rede através da manifestação do riso alheio. Apesar deste modo de propagação ter uma intenção finalística menos deliberativa por parte de quem participa, consideramos que ele também serviu como forma de evidenciamento questões percebidas na publicação original. Ainda que de maneira oblíqua, o humor exerceu um papel importante na difusão do debate sobre certos temas sociais relevantes, como diversidade cultural, imperialismo linguístico, soberania nacional, multiculturalismo, globalização e ética global.

Em geral, os usuários interessados em criar humor a partir desta história passaram a propor novos diálogos entre os personagens da situação, resultando numa atualização do evento a outros enquadramentos circunstanciais (FIG. 5). A marca textual "Agora em Botafogo", que abre o conto e que originalmente servia para localizar o leitor do ambiente onde ocorre o fato, passou a exercer a função de elemento de identificação das adaptações que 
se inseriam e formavam o meme, se mantendo estável em praticamente todas as publicações deste tema que foram coletadas. Ou seja, ao invés de designar o bairro onde o fato acontece, a expressão passa a representar a marca das adaptações que derivam de uma mesma postagem.

\section{AGORA EM BOTAFOGO}

gringo: could you give me an information? eu: To chegando com os refri rapaziada gringo: what eu: Deus é TOP gringo: wtf?

snap: cleyttu Qcleyti AGORA EM BOTAFOGO

Gringo: I can't say

Eu: nossa eu tbm to cansado num guento mais
Agora em Botafogo

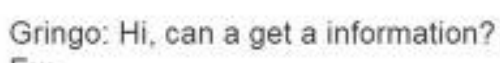

Eu:

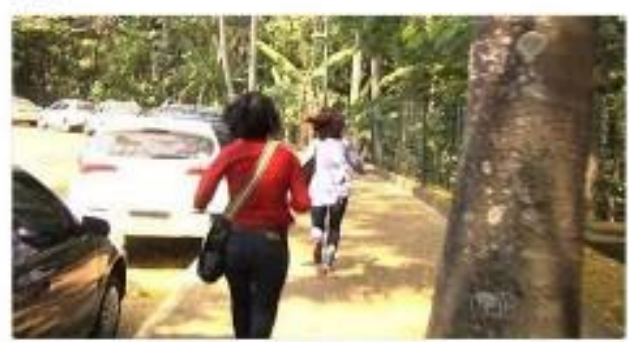

Figura 5 - Usuários atualizam os diálogos com personagem "gringo". Fonte: https://goo.gl/JY4CAi . Acesso em: 20/02/2017.

Diferente dos outros eventos espalhados em sites de redes sociais, este não surgiu na mídia tradicional para posteriormente ser apropriado pelos usuários. A profanação midiática é perceptível desde a publicação matriz, aquela que deu origem às mais diversas adaptações, pois tem como autora uma pessoa comum, narrando um caso particular, dispensando o intermédio ou tutela de veículos de comunicação consagrados.

O que particulariza este caso especificamente é a falta de previsibilidade dos fatores que, oportunizados pelo próprio desenvolvimento da obra, proporcionam as condições necessárias para o surgimento de um movimento circulatório coletivamente agenciado. Outro caso com esta mesma característica é decorrente da mentira contada por um grupo de atletas norte-americanos. Quatro nadadores relataram que foram assaltados quando estavam num táxi voltando para a Vila Olímpica. No entanto, segundo investigação da Polícia Civil, eles teriam se envolvido em uma briga com seguranças de um posto de gasolina no bairro Barra da Tijuca. Assim como os casos anteriores, este se estendeu para além do universo narrativo estrito das Olimpíadas e também não era facilmente previsível aos múltiplos autoresparticipantes da obra.

O que ocorreu a partir de então foi uma onda de apropriações e adaptações humorísticas que tinham como intuito ironizar a atitude deste grupo de "gringos" no Brasil. 
Enquanto algumas publicações inseriam os rostos dos nadadores em notas de três reais, outras comparavam-lhes ao personagem fictício Pinóquio e à grávida de Taubaté. Em outras

a dos atletas era usada como repertório cultural para abordar

esses nadadores dos eua acham q é rsas, como numa postagem que consistia na captura de tela de de boa chegar aqui e tentar enganar a gente pois tem q aprender mt ainda com ela:

radadores dos EUA querem mentir no país do: primeiro a gente em referência ao discurso vigente por parte dos apoiadores do

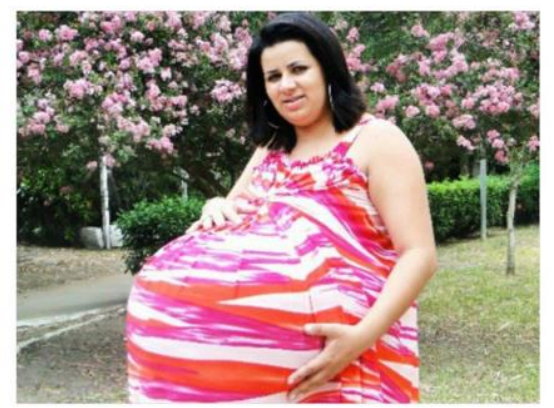
que ela seria apenas a primeira a deixar o cargo (figura 6).
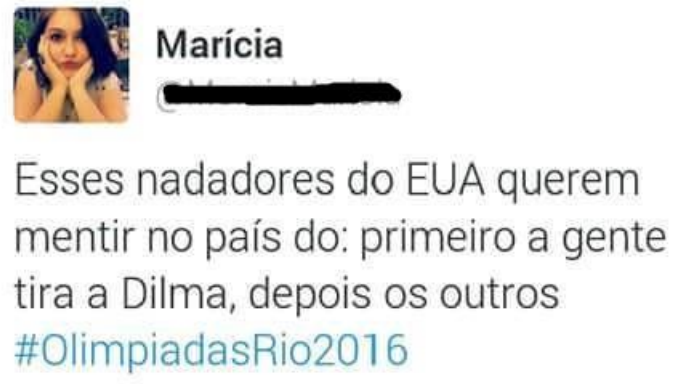

Figura 6 - usuários comparam atitude de nadadores com a de outros indivíduos. Fontes: https://goo.gl/3iV3la ; https://goo.gl/mGNTkm . Acesso em: 23/03/2017

Em geral, todas estas comparações tinham como objetivo enfatizar o falseamento de informação por parte dos nadadores (quando estes apareceram com centralidade na adaptação proposta) ou de outro grupo de pessoas (quando o caso era usado como repertório cultural).

O percurso circulatório foi semelhante aos outros casos descritos anteriormente, com algumas particularidades: após o anúncio do caso por veículos de comunicação de massa, primeiro levantou-se um debate público sobre a ação dos envolvidos e o papel dos demais agentes (no caso, a polícia e o Estado brasileiro), posteriormente a repercussão foi atualizada pelos usuários por meio de adaptações jocosas do ocorrido e, por fim, os veículos de comunicação noticiaram e recuperaram alguns dos casos de apropriação numa tentativa de organizar o fluxo disperso e caótico de adaptações.

\section{CONSIDERAÇÕES FINAIS}


O desenvolvimento das Olimpíadas potencializou uma série de acontecimentos, como o aumento no número de turistas no Brasil e o protagonismo que o país recebeu na mídia internacional. Estes acontecimentos escapam ao próprio limite daquilo que previamente delimitava a obra, expandindo este limite inicial na mesma medida em que expõe novas pautas para discussão na esfera pública. Fatores como atritos culturais entre brasileiros e turistas estrangeiros já existiam antes das Olimpíadas, mas foram intensificados e ganharam mais destaque com a realização do evento e, sobretudo, a partir da interação que pessoas faziam com ele.

A publicação da menina que se recusou a ajudar o "gringo" poderia ter ocorrido em qualquer outro momento; a citação às Olimpíadas na publicação não é substancial ao ocorrido e poderia ser substituída. $\mathrm{O}$ fato em si não guarda qualquer relação de dependência com a obra em questão, mas a própria maneira com que diversos agentes desenvolveram-na acabou por condicionar uma série de fatores previamente ocultos, que impactaram e formataram novas possibilidades narrativas. Mesmo quando as adaptações populares não faziam referência a elementos próprios dos Jogos Olímpicos, elas acabavam sendo inseridas no bojo que abarca a obra cultural em questão, por força do interesse dos usuários participantes.

A prática profanatória comunicativa possibilitada pelas diferentes estruturas de conversação em rede se mostrou uma fonte propícia para repensar o paradigma comunicacional. Neste cenário, no qual os sujeitos podem construir novos fluxos comunicativos pelas bordas, o humor aparece como técnica para uma inovação narrativa potencialmente menos perlocucionária. Partindo do entendimento da profanação enquanto ação política de retomada das capacidades midiáticas pelos indivíduos, um dos propósitos da pesquisa foi abordar a incorporação popular de temáticas sociais no prolongamento narrativos de obras em circulação na web. $\mathrm{O}$ prolongamento de obras culturais midiáticas no ambiente digital é entendido como consequência deste processo.

Os esforços para compreender a formação desse novo cenário não esgotam o fenômeno em si, mas apontam direcionamento para futuras investigações. Encerramos nossa investigação com pontos abertos, tais como, as estratégias de retorno do controle autoralmidiático por parte dos grandes produtores de conteúdo, bem como as intenções e consequências de veículos jornalísticos ao noticiarem as ações dos usuários participantes.

De toda sorte, o humor demonstrou ter uma característica nos espalhamentos em análise e, especificamente, na promoção de debates sociais. Notamos que o recurso satírico age como um tipo particular de participação, que tem a capacidade de incluir tópicos de 
reforço à obra e temas negligenciados ou limitados em seus modos de apresentação. A introdução desses tópicos em obras culturais com grande circulação participativa pode ocorrer atrelada primeiramente à lógica da "zuera" (BARBOSA, 2015), fazendo com que temáticas sociais venham a aderir ao movimento de construção dialógica e coletiva, de maneira a adentrarem na arena de discussão pública.

Existiu, no entanto, um limite na competência deste modo de humor para a manutenção dos tópicos sociais num lugar de destaque na esfera pública. De modo geral, o humor age mais na manutenção destes temas na constituição da obra do que na resolução de conflitos, podendo inclusive mobilizar o posicionamento dos usuários e a tomada de uma posição política por meio do uso criativo da palavra. É, portanto, um meio de conservação de temas em evidência através da desestabilização constante de elementos de obras de mídia.

As controvérsias não são apenas atualizadas, como também se tornam mais relevantes ao serem agregadas a uma obra em espalhamento no ambiente midiático, por meio do recurso humorístico. Esta forma de instabilidade é característica própria das polêmicas destacadas por usuários ao longo dos processos profanatórios das manifestações culturais analisadas. Na web, a gíria "treta" é constantemente ressaltada para abordar uma prática participativa na qual o usuário se dispõe a se envolver numa discussão enérgica. Neste sentido, diz respeito a briga, confusão, desentendimento ou bagunça.

A treta atrelada ao humor se consolida como um exercício particular de provocação do status quo na esfera digital e pode ser entendida como expressão evidente da profanação midiática nas redes sociais digitais, uma vez que ocorre pela exposição crítica de um assunto que não ganharia tanta visibilidade na imprensa tradicional. Ou seja, o humor serve como mote para inserção de controvérsias na pauta do dia, mas dificilmente possibilita a resolução destes conflitos.

\section{REFERÊNCIAS}

AGAMBEN, Giorgio. O que é o Contemporâneo? E outros ensaios. Tradução, Vinícius Nicastro Honesko. Chapecó: Argos, 2009.

Profanações. Tradução, Selvino José Assmann. São Paulo: Boitempo, 2007.

AMARAL, Adriana; BARBOSA, Camila; POLIVANOV, Beatriz. Subculturas, re(a)presentação e autoironia em sites de rede social: o caso da fanpage "Gótica Desanimada" no Facebook. Revista Lumina: Juiz de Fora, UFJF, v 9, n 2, 2015, pp. 1-18. 
BAKHTIN, Mikhail. Estética da Criação Verbal. Tradução do Francês, Maria Ermantina Galvão G. Pereira. São Paulo: Martins Fontes, 1997.

. Marxismo e filosofia da linguagem. 2 ed. São Paulo: HUCIT, 1981

BARBOSA, Camila Cornutti. Celebridades e Apropriações Humorísticas em Blogs: Uma análise do "Morri de Sunga Branca" e do "Te dou um dado?". 306 f. Tese (Doutorado em Comunicação e Informação) - Programa de Pós-Graduação em Comunicação e Informação, Universidade Federal do Rio Grande do Sul, Porto Alegre. 2015.

BOURDIEU, Pierre. Os Jogos Olímpicos. In: BOURDIEU, Pierre. Sobre a televisão. Tradução, Maria Lúcia Machado. Rio de Janeiro: Jorge Zahar Ed., 1997, pp. 121-128.

COELHO, Teixeira. A Cultura e seu Contrário: Cultura, arte e política pós-2001. São Paulo: Iluminuras, 2008.

DALMONTE, Edson; QUEIROZ, Caio; SOUZA, Pedro Carlos. Espalhamento Midiático e Profanação: uma análise de memes sobre o debate eleitoral de 2014. Anais do XXIV Encontro Anual da Compós (Associação Nacional dos Programas de Pós-Graduação em Comunicação). Universidade de Brasília, Brasília (DF), 2015.

DALMONTE, Edson. Discurso e mobilização social no contexto das tecnologias interativas: a emergência de múltiplas esferas argumentativas. Revista Comunicação Mídia e Consumo: São Paulo, ESPM, v 9, n 24, 2012, pp. 13-31.

. A esfera paratextual: o lugar do leitor-participante no webjornalismo. Revista Galáxia: São Paulo, PUC-SP, n. 18, 2009a, pp.113-124.

DEUZE, Mark. Media Life. Cambridge: Polity Press, 2013.

FECHINE, Yvana; MOREIRA, Diego G. Dispositivo midiático de participação nas interações transmídias: explorando o conceito a partir das ações da Rede Globo. Anais do XXIV Encontro Anual da Compós (Associação Nacional dos Programas de Pós-Graduação em Comunicação). Universidade de Brasília, Brasília, 2015.

FELINTO, Erick. Videotrash: o YouTube e a cultura do "spoof" na internet. Revista Galáxia: São Paulo, PUC-SP, n. 16, dez. 2008, pp. 33-42.

FOUCAULT, Michel. Segurança, Território, População: curso dado no Collège de France (19771978). Tradução, Eduardo Brandão. São Paulo: Martins Fontes, 2008.

Vigiar e Punir: nascimento da prisão. Tradução, Raquel Ramalhete. Petrópolis: Vozes, 1997.

GENETTE, Gerárd. Paratextos Editoriais. Tradução, Álvaro Faleiros. Cotia, SP: Ateliê Editorial, 2009.

Palimpsestos: La literatura en segundo grado. Tradução, Celia Fenández Prieto. Madrid: Taurus, 1989.

HEPP, Andreas; HJARVARD, Stig; LUNDBY, Knut. Mediatization: theorizing the interplay between media, culture and society. Media, Culture \& Society, v. 37, n. 2, 2015, pp. 314-324.

HJARVARD, Stig. Midiatização: teorizando a mídia como agente de mudança social e cultural.

Revista Matrizes: São Paulo, USP, ano 5, n 2, 2012, pp. 53-91. 
HUTCHEON, Linda. O Carnavalesco e a Narrativa Contemporânea: Cultura popular e erotismo. In: RIBEIRO, Ana Paula Goulart; SACRAMENTO, Igor (org.). Mikhail Bakhtin: Linguagem, cultura e mídia. São Carlos: Pedro \& João Editores, 2010, pp.257-275.

JENKINS, Henry; FORD, Sam \& GREEN, Joshua. Spreadable Media: creating value and meaning in a networked culture. Nova York: New York University Press, 2013.

JOHNSON, Steven. Cultura da Interface: como o computador transforma nossa maneira de criar e comunicar. Tradução, Maria Luiza X. de A. Borges. Rio de Janeiro: Jorge Zahar Editor, 2001.

KLEIN, Otavio José. A gênese do conceito de dispositivo e a sua utilização nos estudos mediáticos. Estudos em Comunicação, v. 1, 2007, pp. 1-17.

KRISTEVA, Julia. A Palavra, o Diálogo e o Romance. In: KRISTEVA, Julia. Introdução à Semanálise. São Paulo: Editora Perspectiva, 1974, pp. 61-90.

SENELLART, Michel. Situação dos Cursos. In: FOUCAULT, Michel. Segurança, Território, População: curso dado no Collège de France (1977-1978). Tradução, Eduardo Brandão. São Paulo: Martins Fontes, 2008, pp. 495-538.

SHIFMAN, L. Memes in Digital Culture. The MIT Press Essential Knowledge series. Boston: MIT Press, 2014.

SHIRKY, Clay. A Cultura da Participação: Criatividade e generosidade no mundo conectado. Tradução, Celina Portocarrero. Rio de Janeiro: Zahar, 2011.

ZAGO, Gabriela. A participação dos Integrantes nos Sites de Redes Sociais como uma Dimensão do Acontecimento Jornalístico. Revista Intexto: Porto Alegre, UFRGS, n. 28, julho 2013, pp. 156-170.

Original recebido em: 19 de novembro de 2016

Aceito para publicação em: 19 de setembro de 2017

\section{Edson Fernando Dalmonte}

Doutor em Comunicação e Cultura Contemporâneas pela Universidade Federal da Bahia (2008). Professor da Faculdade de Comunicação e do Programa de Pós-graduação em Comunicação e Cultura Contemporâneas da Universidade Federal da Bahia.

\section{Pedro Carlos Ferreira de Souza}

Doutorando em Comunicação e Cultura Contemporâneas pela Universidade Federal da Bahia e mestre pela mesma instituição. Membro do ANALÍTICA - Crítica de Mídia, Estética e Produtos Midiáticos. 